\title{
Hypoxaemia on arrival in a multidisciplinary intensive care unit
}

\author{
K de Vasconcellos, MB ChB, FCA (SA), Cert Crit Care (SA); D L Skinner, MB ChB, FCS (SA), MMed (Surg); \\ D Singh, MB ChB, FCA (SA), Cert Crit Care (SA) \\ Department of Critical Care, King Edward VIII Hospital, Durban, South Africa, and Department of Anaesthesiology and Critical Care, \\ School of Clinical Medicine, College of Health Sciences, Nelson R Mandela School of Medicine, University of KwaZulu-Natal, Durban
}

Corresponding author: K de Vasconcellos (kimdevasconcellos@gmail.com)

\begin{abstract}
Background. Transport of the critically ill patient poses the risk of numerous complications. Hypoxaemia is one such serious adverse event and is associated with potential morbidity and mortality. It is, however, potentially preventable.

Objective. To determine the incidence of hypoxaemia on arrival in a tertiary multidisciplinary intensive care unit (ICU) and to identify risk factors for this complication.

Method. A retrospective observational study was conducted at King Edward VIII Hospital, Durban, South Africa, from May 2013 to February 2014.

Results. Hypoxaemia occurred in $15.5 \%$ of admissions sampled. Statistically significant risk factors for hypoxaemia on univariate analysis $(p<0.05)$ included lack of peripheral capillary oxygen saturation $\left(\mathrm{SpO}_{2}\right)$ monitoring, transfer by an intern as opposed to other medical/ paramedical staff, and transfer from internal medicine. Use of neuromuscular blockers and transfer from theatre were protective. Binary logistic regression analysis revealed lack of $\mathrm{SpO}_{2}$ monitoring to be the only significant independent predictor of hypoxaemia (odds ratio 6.1; 95\% confidence interval $1.5-24.5 ; p=0.02$ ).

Conclusion. Hypoxaemia is common on admission to the ICU and may be prevented by simple interventions such as appropriate transport monitoring.
\end{abstract}

S Afr Med J 2016;106(5):510-513. DOI:10.7196/SAMJ.2016.v106i5.10251

Critical care beds are a scarce resource internationally, but especially in South Africa (SA), where in 2008 - 2009 there were 4719 critical care beds for a population of 49 million. ${ }^{[1]}$ Of note, only 1186 of these beds were in the public sector, which services the bulk of the population. In addition, these numbers include both high-care and intensive care beds. The natural consequence of the above is that demand for intensive care unit (ICU) beds exceeds supply. Difficult triage decisions therefore need to be made to ensure that the patients most likely to benefit from a stay in the ICU are admitted.

Once a decision is made to admit a patient to an ICU, a key component of optimising their outcome (and ensuring optimal use of the scarce resource) is to ensure safe transport to the ICU. This is technically and logistically challenging and often occurs during a period of significant physiological disturbance. Complications are therefore to be anticipated. The exact incidence of complications varies greatly depending on the setting and the definition of a transport-related adverse event. There are no relevant data for critically ill adults in SA.

A number of factors can potentially contribute to a high incidence of transport-related complications. Firstly, only $23 \%$ of state hospitals have ICUs, which means that patients will require inter-hospital ambulance transfer. ${ }^{[1]}$ These transfers are conducted by advanced life-support paramedics and have no critical care-trained doctor in attendance. Secondly, critical care does not constitute a significant component of undergraduate teaching and is not a requirement for intern training. In addition, only anaesthesiology and the surgical disciplines have a requirement for at least 3 months of critical care training as a component of their 4-year specialist training programmes. The net result is that many, if not most, of the doctors treating and transferring critically ill patients have had no or inadequate critical care training.
The clinical relevance of many reported adverse events is unclear. Hypoxaemia was chosen as the index adverse event for this study, as it is a major adverse event with potential profound multisystem effects for the critically ill patient. In addition, in studies that report the incidence of hypoxaemia, the incidence is high (8.8 - 13\%), and as oxygen saturation is readily and objectively measured with pulse oximetry, hypoxaemia is a readily identifiable complication. ${ }^{[2,3]}$

Transport-related adverse effects are potentially amenable to quality improvement programmes, and identification of clinically important complications and potentially modifiable risk factors is an important research goal. ${ }^{[4]}$ It was considered important to identify whether hypoxaemia was an important adverse event during transport of critically ill patients in our setting, and if so to identify risk factors for this complication. These could then be used to target appropriate interventions and potentially improve both outcomes for our critically ill patients and utilisation of a scarce resource.

\section{Methods}

We conducted a retrospective observational review of data obtained during a prospective audit on the transport of patients admitted to the ICU at King Edward VIII Hospital, Durban, SA, during the period May 2013 - February 2014. This is a 12-bed, multidisciplinary teaching ICU that receives admissions from within the hospital and throughout the province of KwaZulu-Natal, with a population base of approximately 11 million people.

All patients admitted during the audit period were eligible for inclusion, but this was dependent on staffing and clinical demands in the unit and was at the discretion of the admitting doctor. The audit data collection tool consisted of a single A4-page case report form consisting of basic demographic data, transport variables and complication variables. This was completed on arrival of the patient 
in the ICU and was to reflect the patient's status on arrival in the ICU. Data from completed case report forms were then entered into an Excel spreadsheet.

Approval for the study was obtained from the University of KwaZulu-Natal Biomedical Research Ethics Committee, King Edward VIII Hospital, and the Provincial Health and Research Ethics Committee of the KwaZulu-Natal Department of Health.

Demographic data, transport data and data related to the primary outcome (hypoxaemia) were extracted from the Excel spreadsheet. All cases were included in the study. Hypoxaemia was defined as a peripheral capillary oxygen saturation $\left(\mathrm{SpO}_{2}\right)$ of $<90 \%$, using pulse oximetry.

Potential risk factors extracted from the demographic and transport data included the following:

- Time of transfer

- Accompanying personnel

- Referring discipline

- Intra/inter-hospital transfer

- Monitoring:

- $\mathrm{SpO}_{2}$

- non-invasive blood pressure

- electrocardiography (ECG)

- Airway management including major airway complications

- Ventilatory method

- Use of sedatives and muscle relaxants.

Statistical analysis was performed using SPSS version 22. All data were categorical data and were analysed using descriptive statistics and presented as percentages. Data were analysed using Fisher's exact test, Pearson's $\chi^{2}$ test or the $Z$-test of column proportions, where appropriate.

All risk factors with a univariate association of $p<0.1$ with the study outcome were entered into multivariate analysis, using binary logistic regression. A backward stepwise modelling technique was used, based on likelihood ratios. The odds ratio (OR) for the primary outcome and the $95 \%$ confidence intervals (CIs) are reported.

\section{Results}

Data were available for 148 transfers. Of these patients, 23 (15.5\%) were hypoxaemic on arrival in the ICU. Four (17.4\%) of these patients had a major airway adverse event.

The baseline transfer characteristics of the cohort are set out in Table 1. Of note, the majority of transfers were in-hospital transfers (61.5\%) and occurred after hours (71.0\%).

Registrars and paramedics were the most common transferring personnel (38.8\% each). $\mathrm{SpO}_{2}$ monitoring was absent in $10.8 \%$ of patients, blood pressure monitoring in $14.9 \%$ and ECG monitoring in $16.2 \%$. Inadequate monitoring (as defined by the absence of $\mathrm{SpO}_{2}$, ECG or blood pressure monitoring) was noted in 38 patients (25.7\%). The majority of the patients were intubated (85.8\%), with mode of ventilation varying between spontaneous breathing $(17.8 \%)$, use of a selfinflating bag (37.0\%) and use of a transport ventilator (45.2\%). Of the intubated patients, 5 (4.0\%) were breathing spontaneously, 54 (43.2\%) were ventilated with a self-inflating bag and $66(52.8 \%)$ were ventilated with a transport ventilator. In terms of medication received for or during transfer, $45.9 \%$ of patients received inotropes, $58.5 \%$ sedatives and $18.4 \%$ muscle relaxants. Of the 19 inpatient transfers in which muscle relaxants were used, all but one of the patients were referred from anaesthesia.

The results of the risk factor analyses are listed in Table 2. Of note, failure to monitor $\mathrm{SpO}_{2}$ during transfer was associated with an increased incidence of hypoxaemia ( $37.5 \%$ v. $13.0 \%$; $p=0.02)$. The use of muscle relaxants was associated with a lower incidence of hypoxaemia $(0 \% \mathrm{v}$.
$18.3 \% ; p=0.01)$. Transfer by an intern $v$. any other healthcare personnel was associated with an increased incidence of hypoxaemia $(45.5 \% \mathrm{v}$. $13.2 \%$; $p=0.02$ ). While transfer from internal medicine was associated with an increased incidence of hypoxaemia (36.8\% v. $13.2 \%$; $p=0.039)$, transfer from anaesthesia was associated with a lower incidence $(9.3 \% \mathrm{v}$. $27.3 \% ; p=0.031)$. There was no significant difference in the incidence of hypoxaemia according to type of transfer (in-hospital v. inter-hospital), time of transfer, presence or absence of ECG monitoring, presence or absence of blood pressure monitoring, mode of ventilation, airway management, use of inotropes or use of sedatives.

The only variable that remained significant on multivariate analysis was $\mathrm{SpO}_{2}$ monitoring, with lack of $\mathrm{SpO}_{2}$ monitoring having an OR of 6.1 (95\% CI 1.5 - 24.5; $p=0.01$ ) for hypoxaemia for the whole cohort and an OR of 4.2 (95\% CI $1.3-13.6 ; p=0.02)$ for hypoxaemia in the in-hospital subgroup.

Table 1. Transfer characteristics of patients admitted to the King Edward VIII ICU

\begin{tabular}{|c|c|c|}
\hline Variable & Category & $n(\%)$ \\
\hline \multirow{2}{*}{ Type of transfer } & In-hospital & $91(61.5)$ \\
\hline & Inter-hospital & $57(38.5)$ \\
\hline \multirow[t]{3}{*}{ Time of transfer } & $08 \mathrm{~h} 00-16 \mathrm{~h} 00$ & $43(29.1)$ \\
\hline & $16 \mathrm{~h} 00-00 \mathrm{~h} 00$ & $66(44.6)$ \\
\hline & $00 \mathrm{~h} 00-08 \mathrm{~h} 00$ & $39(26.4)$ \\
\hline \multirow{4}{*}{$\begin{array}{l}\text { Referring discipline } \\
\text { (in-hospital) }\end{array}$} & Medicine & $19(21.8)$ \\
\hline & Surgery & $16(18.4)$ \\
\hline & O\&G & $9(10.3)$ \\
\hline & Anaesthesia & $43(49.4)$ \\
\hline \multirow[t]{6}{*}{ Accompanying personnel } & Consultant & $5(3.4)$ \\
\hline & Registrar & $57(38.8)$ \\
\hline & Nurse & $8(5.4)$ \\
\hline & Medical officer & $9(6.1)$ \\
\hline & Paramedic & $57(38.8)$ \\
\hline & Intern & $11(7.5)$ \\
\hline \multirow[t]{2}{*}{$\mathrm{SpO}_{2}$ monitoring } & Yes & $131(89.1)$ \\
\hline & No & $16(10.9)$ \\
\hline \multirow[t]{2}{*}{ ECG monitoring } & Yes & $124(83.8)$ \\
\hline & No & $24(16.2)$ \\
\hline \multirow[t]{2}{*}{$\mathrm{BP}$ monitoring } & Yes & $126(85.1)$ \\
\hline & No & $22(14.9)$ \\
\hline \multirow[t]{3}{*}{ Mode of ventilation } & Spontaneous & $26(17.8)$ \\
\hline & Self-inflating bag & $54(37.0)$ \\
\hline & Transport ventilator & $66(45.2)$ \\
\hline \multirow[t]{2}{*}{ Airway management } & ETT & $127(85.8)$ \\
\hline & Unprotected & $21(14.2)$ \\
\hline \multirow[t]{2}{*}{ Inotropes } & Yes & $68(45.9)$ \\
\hline & No & $80(54.1)$ \\
\hline \multirow[t]{2}{*}{ Sedatives } & Yes & $86(58.5)$ \\
\hline & No & $61(41.5)$ \\
\hline \multirow[t]{2}{*}{ Muscle relaxants } & Yes & $27(18.4)$ \\
\hline & No & $120(81.6)$ \\
\hline
\end{tabular}




\section{Discussion}

Hypoxaemia is a significant complication during the transfer of critically ill patients. The incidence of hypoxaemia in this cohort of patients is in keeping with incidences quoted previously. ${ }^{[2,3]}$ Direct

\begin{tabular}{|c|c|c|c|}
\hline Variable & Category & $\begin{array}{l}\text { Hypoxaemia, } \\
n(\%)\end{array}$ & $p$-value \\
\hline \multirow[t]{2}{*}{ Type of transfer } & In-hospital & $17(18.7)$ & 0.18 \\
\hline & Inter-hospital & $6(10.5)$ & \\
\hline \multirow[t]{3}{*}{ Time of transfer } & $08 \mathrm{~h} 00-16 \mathrm{~h} 00$ & $6(14.0)$ & 0.93 \\
\hline & $16 \mathrm{~h} 00-00 \mathrm{~h} 00$ & $11(16.7)$ & \\
\hline & $00 \mathrm{~h} 00-08 \mathrm{~h} 00$ & $6(15.4)$ & \\
\hline \multirow{4}{*}{$\begin{array}{l}\text { Referring } \\
\text { discipline } \\
\text { (in-hospital) }\end{array}$} & Medicine & $7(36.8)$ & 0.06 \\
\hline & Surgery & $4(25.0)$ & \\
\hline & O\&G & $1(11.1)$ & \\
\hline & Anaesthesia & $4(9.3)$ & \\
\hline \multirow{2}{*}{$\begin{array}{l}\text { Medicine } \\
\text { v. other } \\
\text { (in-hospital) }\end{array}$} & Medicine & $7(36.8)$ & $0.04^{*}$ \\
\hline & Other & $9(13.2)$ & \\
\hline \multirow{2}{*}{$\begin{array}{l}\text { Anaesthesia } \\
\text { v. other } \\
\text { (in-hospital) }\end{array}$} & Anaesthesia & $4(9.3)$ & $0.03^{*}$ \\
\hline & Other & $12(27.3)$ & \\
\hline \multirow{6}{*}{$\begin{array}{l}\text { Accompanying } \\
\text { personnel }\end{array}$} & Consultant & $0(0.0)$ & 0.08 \\
\hline & Registrar & $10(17.5)$ & \\
\hline & Nurse & $1(12.5)$ & \\
\hline & Medical officer & $1(11.1)$ & \\
\hline & Paramedic & $6(10.5)$ & \\
\hline & Intern & $5(45.5)$ & \\
\hline \multirow[t]{2}{*}{ Intern v. other } & Intern & $5(45.5)$ & $0.02^{*}$ \\
\hline & Other & $18(13.2)$ & \\
\hline \multirow[t]{2}{*}{$\mathrm{SpO}_{2}$ monitoring } & Yes & $17(13.0)$ & $0.02^{*}$ \\
\hline & No & $6(37.5)$ & \\
\hline \multirow[t]{2}{*}{ ECG monitoring } & Yes & $17(13.7)$ & 0.21 \\
\hline & No & $6(25)$ & \\
\hline \multirow[t]{2}{*}{ BP monitoring } & Yes & $17(13.5)$ & 0.11 \\
\hline & No & $6(27.3)$ & \\
\hline \multirow{3}{*}{$\begin{array}{l}\text { Mode of } \\
\text { ventilation }\end{array}$} & Spontaneous & $3(11.5)$ & 0.49 \\
\hline & Self-inflating bag & $11(20.4)$ & \\
\hline & Transport ventilator & $9(13.6)$ & \\
\hline \multirow{2}{*}{$\begin{array}{l}\text { Airway } \\
\text { management }\end{array}$} & ETT & $21(16.5)$ & 0.53 \\
\hline & Unprotected & $2(9.5)$ & \\
\hline \multirow[t]{2}{*}{ Inotropes } & Yes & $12(17.6)$ & 0.51 \\
\hline & No & $11(13.8)$ & \\
\hline \multirow[t]{2}{*}{ Sedatives } & Yes & $11(12.8)$ & 0.38 \\
\hline & No & $11(18.0)$ & \\
\hline \multirow[t]{2}{*}{ Muscle relaxants } & Yes & $0(0.0)$ & $0.01^{*}$ \\
\hline & No & $22(18.3)$ & \\
\hline
\end{tabular}

comparison between the studies is not appropriate, however, because of different methodologies and patient populations. Transportrelated complications, and hypoxaemia in particular, are therefore a significant public health problem in the SA adult critical care population and an important target for preventive measures.

A rational approach to this problem starts with identifying risk factors that may be amenable to intervention. In this regard we found on univariate analysis that patients transferred from internal medicine had a significantly higher incidence of hypoxaemia than the other disciplines combined, whereas those transferred by anaesthetists/from theatre had a significantly lower incidence. This may reflect differences in knowledge and training of staff, with anaesthetists perceived to have more experience in transferring critically ill patients. However, the difference may simply reflect a difference in patient population, with patients from internal medicine being more likely to present with an underlying cardiopulmonary disorder predisposing them to hypoxaemia. These factors were not evaluated in this study, but these results do suggest that any future interventions should be rolled out to the highest-risk disciplines first.

Patients transferred by interns also had a significantly higher risk of hypoxaemia on univariate analysis. This highlights the potential risk of allowing inexperienced staff to transfer critically ill patients.

A surprising finding was that the use of muscle relaxants was associated with a significantly decreased incidence of hypoxaemia. In contrast, there was no difference with the use of sedative medication. This may be because muscle relaxation provides superior transferring conditions, with less risk of patient-ventilator dyssynchrony and airway complications. However, of the 19 in-hospital transfers in which muscle relaxants were used, all but one of the patients were transferred from anaesthesia/theatre, and the lower incidence of hypoxaemia may therefore simply reflect the lower risk in this patient group. While the routine use of neuromuscular blockade cannot be advocated solely on the basis of these findings, its use remains reasonable if it is required to achieve safe transporting conditions.

The use of saturation monitoring during transfer was the only variable that remained significant on multivariate analysis, with lack of saturation monitoring being associated with an increased risk of hypoxaemia on arrival in the ICU. While this may seem an intuitive finding, it highlights the axiom that a problem can only be detected if it is looked for. Whether the failure to use $\mathrm{SpO}_{2}$ monitoring was due to a lack of knowledge on the part of the transferring personnel or a lack of appropriate equipment is not clear from this study. However, both will need to be addressed in any future interventions.

There was no statistically significant difference in the incidence of hypoxaemia between in-hospital and inter-hospital transfers; in fact, the trend was towards a higher incidence in in-hospital transfers. This has a number of potential explanations: patients may be transferred in-hospital when they are considered too unstable to transfer between hospitals; there may be less attention to detail in in-hospital transfers owing to the perceived proximity to the ICU; the profile of patients transferred may be different; and the transferring personnel may be a factor, as inter-hospital transfers are performed by generally experienced paramedics, whereas in-hospital transfers may be attempted by inexperienced interns. Whatever the underlying reason, this finding highlights the fact that in-hospital transfers are at least as hazardous as inter-hospital transfers and that appropriate training of hospital personnel is required to improve the quality and safety of in-hospital transfers.

\section{Study limitations}

The study is a retrospective analysis of data collected during a prospective audit. There is therefore a potential for the biases 
inherent in retrospective studies, but the prospective collection of data for the audit mitigates against this. Inclusion of patients in the study was at the discretion of the admitting doctor, resulting in potential sampling bias. As mentioned previously, the study only evaluated hypoxaemia on arrival in the ICU and did not include complications en route. The study is a single-centre study, but the study ICU is a busy tertiary ICU providing a provincial ICU service and the findings are therefore likely be generalisable beyond the study ICU.

\section{Conclusion and recommendations}

Hypoxaemia is a significant risk during the transfer of critically ill patients. Numerous potential risk factors were identified, the most robust being lack of appropriate transport monitoring. Many of these risk factors are potentially modifiable through appropriate training and exposure to critical care at both undergraduate and postgraduate level, and through provision of necessary transport equipment. Further multicentre studies are required to confirm and expand upon these findings, to evaluate the effect of transport-related adverse events on patient outcome, and to measure the efficacy of intervention programmes. In the interim, simple training and infrastructure improvement programmes may enhance the safety of critically ill patients.

\section{References}

1. Naidoo K, Singh J, Lalloo U. A critical analysis of ICU/HC beds in South Africa: 2008-2009. S Afr Med 2013;103(10):751-753. DOI:10.7196/SAMJ.6415

2. Parmentier-Decrucq E, Poissy J, Favory R, et al. Adverse events during intrahospital transport of critically ill patients: Incidence and risk factors. Ann Intensive Care 2013;3(1):10. DOI:10.1186/21105820-3-10

. Hatherill M, Waggie Z, Reynolds L, Argent A. Transport of critically ill children in a resource-limited setting. Intensive Care Med 2003;29(9):1547-1554. DOI:10.1007/s00134-003-1888-7

4. Berube M, Bernard F, Marion $\mathrm{H}$, et al. Impact of a preventive programme on the occurrence of incidents during the transport of critically ill patients. Intensive Crit Care Nurs 2013;29(1):9-19. DOI:10.1016/j.iccn.2012.07.00

Accepted 2 November 2015 